\title{
Processability and Electrical Characteristics of Glass Substrates for RF Wafer-Level Chip-Scale Packages
}

\author{
A. Polyakov, P.M. Mendes*, S.M. Sinaga, M. Bartek, B. Rejaei, J.H. Correia*, J.N. Burghartz \\ Delft University of Technology, DIMES/ECTM \\ Feldmannweg 17, 2628CT, Delft, The Netherlands \\ Phone: +31 1527 89421, Fax: +31 1526 22163, E-mail: a.polyakov@dimes.tudelft.nl \\ * University of Minho, Department of Industrial Electronics, Minho, Portugal
}

\begin{abstract}
Various types of glass substrates have been compared with respect to their suitability as a low-loss substrate in waferlevel chip-scale packaging for RF applications. Processability has been evaluated by fabrication of shallow and deep recesses using wet etching in $\mathrm{HF}\left(/ \mathrm{H}_{3} \mathrm{PO}_{4}\right)$ solutions. Electrical characteristics (dielectric constant and attenuation) have been extracted from measurements on coplanar wave guides (CPWs) up to $10 \mathrm{GHz}$.

Results show that Corning Pyrex $\# 7740$ glass provides optical quality of wet-etched deep recesses, but exhibit about 2 times higher electrical attenuation than Hoya SD-2. Pyrex \#7740 and SD-2 are thermally matched to silicon and due to some alkali content, they are suitable for anodic bonding. The relatively high content of $\mathrm{Al}_{2} \mathrm{O}_{3}(\sim 20 \%)$ in SD-2 is favorable for its electrical properties, but makes wet etching of deep recesses more difficult. The non-alkaline AF45, with CTE almost 2 times of $\mathrm{Si}\left(\mathrm{CTE}_{\mathrm{AF} 45}=4.5 \times 10^{-6} \mathrm{~K}^{-1}\right)$, is suitable for adhesive bonding and is difficult to pattern using wet etching. Its electrical attenuation is close to that of SD-2. The measured dielectric constants (at $6 \mathrm{GHz}$ ) for SD-2, Pyrex $\# 7740$ and AF45 are 4.7,5.9 and 6.1, respectively.
\end{abstract}

\section{Introduction}

Glass is a popular construction material for microfluidic and sensor devices due to its inertness, stability and transparency. Because of its low dielectric losses, glass is also attractive as a substrate for RF applications. Silicon wafers with RF devices fabricated using IC technology are bonded to planar glass wafers whereupon silicon is being partly removed [1]. This, so called substrate transfer technology, allows to gain all advantages of low losses in glass at RF frequencies, still utilizing conventional silicon technology for device fabrication. Bonding of 3D-structured glass substrate to a core RF silicon wafer with wafer-to-wafer electrical interconnects may enable realization of a variety of novel RF structures (high-Q passives, transmission lines, suspended ground planes, integrated antennas, on-chip shielding, etc.) and represents a truly added value to the concept of waferlevel chip-scale packaging. Shallow and deep recesses in glass wafers are required for certain RF applications. Sufficient separation between the metal structures on the glass and the surface of lossy silicon substrate is required to avoid Eddy currents. Moreover, recesses in glass can also be used for protection of RF MEMS structures [2]. The main problem in fabrication of deep recesses (depth $50-150 \mu \mathrm{m}$ ) in glass substrates is the complex composition of various glass types resulting in rough surfaces and non-uniformity in etching profiles.
Knowledge of accurate electrical parameters of glass substrates is of extreme importance when designing for RF or microwave applications. However, these data are often not available or they are limited to the $\mathrm{MHz}$ range. Possibility to compare various materials in respect of their permittivity and dielectric losses would allow to make the proper choice.

We have studied three types of commercially available glass types (Corning Pyrex 7740, Hoya SD-2 and Schott AF45), as they have coefficients of thermal expansion (CTE) close to silicon (Table 1). This is of importance when siliconto-glass bonding is considered.

Table 1: CTE for silicon and different types of glasses.

\begin{tabular}{|l|c|}
\hline \multicolumn{1}{|c|}{ Glass type } & CTE $\left[\times 10^{-6} / \mathrm{K}\right]$ \\
\hline Silicon & 2.5 \\
\hline Fused Silica $\left(\mathrm{SiO}_{2}\right)$ & 0.5 \\
\hline Pyrex 7740 & 3.25 \\
\hline AF45 & 4.5 \\
\hline SD-2 & 2.5 \\
\hline
\end{tabular}

In this paper, we report results on electrical characterization of these glass types. Permittivity and permeability are extracted from measurements on coplanar waveguides. The processability is characterized by performing wet-etching in HF-based solutions.

\section{Patterning of glass}

Several techniques are well-known for microfluidic device fabrication. However, due to small injection volumes used in these devices, fabricated channels are typically tens of $\mu \mathrm{m}$ in depth. For RF applications deeper cavities (e.g. for sealing RF MEMS) or even through-wafer interconnects might be required. Several methods for glass micromachining may be adopted for RF applications. They are summarized in Table 2.

Powder blasting [3] is the fastest method, making it suitable for mass production. However critical dimensions and roughness of etched surfaces is sometimes insufficient for RF applications. Plasma etching results in very smooth etched surfaces, but due to its limited etch rate, the achievable etch depth is limited. Wet etching is the most common technique used in fabrication of microchannels and can easily be used for fabrication of cavities $>100 \mu \mathrm{m}$ deep. However, the aspect ratio is always close to 1 due to isotropic nature of wet glass etching. Another problem occurring during wet etching is potentially rough surfaces after etching due to the complex glass composition. Mixing HF-solutions with other etchants 
may solve this problem. In this paper results on etching in HF and $\mathrm{HF} / \mathrm{H}_{3} \mathrm{PO}_{4}$ are presented.

Table 2: Overview of glass micromachining techniques.

\begin{tabular}{|l|c|c|c|c|}
\hline \multicolumn{1}{|c|}{ Methods } & $\begin{array}{c}\text { Feature } \\
\text { size }[\mu \mathrm{m}]\end{array}$ & $\begin{array}{c}\text { Aspect } \\
\text { ratio }\end{array}$ & $\begin{array}{c}\text { Rough- } \\
\text { ness }\end{array}$ & $\begin{array}{c}\text { Etch rate } \\
{[\mu \mathrm{m} / \mathrm{min}]}\end{array}$ \\
\hline $\begin{array}{l}\text { Powder } \\
\text { blasting [3] }\end{array}$ & $>50$ & $\sim 3-5$ & Poor & $>20$ \\
\hline $\begin{array}{l}\text { Plasma } \\
\text { etching [4] }\end{array}$ & $>1$ & $>10$ & Good & $<0.5$ \\
\hline Wet etching [5] & $>10$ & 1 & Good & $1-10$ \\
\hline $\begin{array}{l}\text { Laser } \\
\text { drilling [3] }\end{array}$ & $>100$ & $>10$ & Poor & \\
\hline $\begin{array}{l}\text { Mech. methods } \\
\text { (drilling etc)[6] }\end{array}$ & $>300$ & & Poor & \\
\hline
\end{tabular}

\section{Wet etching of glass}

HF-based solutions are well-known etchants of glass. But they may result in rough surfaces after etching due to complex glass composition (Table 3). Complex composition also leads to different behavior of various glass types during etching.

Table 3: Composition of different types of glasses.

\begin{tabular}{|l|c|c|c|c|c|}
\hline \multirow{2}{*}{ Glass name } & \multicolumn{5}{|c|}{ Compounds [\%] } \\
\cline { 2 - 6 } & $\mathrm{SiO}_{2}$ & $\mathrm{~B}_{2} \mathrm{O}_{3}$ & $\mathrm{Al}_{2} \mathrm{O}_{3}$ & $\mathrm{Na}_{2} \mathrm{O}$ & $\mathrm{CaO}$ \\
\hline Fused silica & $\sim 100$ & & & & \\
\hline Pyrex \#7740 & 80 & 13 & 3 & 4 & \\
\hline Hoya SD-2 & 60 & 2 & 25 & 10 & \\
\hline Schott AF45 & 55 & 14 & & - & 30 \\
\hline
\end{tabular}

\section{Experiments}

Three glass types were analyzed: Corning Pyrex \#7740, Hoya SD-2 and Schott AF45. The etching was performed in $10 \%, 20 \%$ and $40 \% \mathrm{HF} / \mathrm{H}_{2} \mathrm{O}$ solutions at room temperature. The etching in 5\% $\mathrm{HF} / \mathrm{H}_{2} \mathrm{O}$ and $\mathrm{HF} / \mathrm{H}_{3} \mathrm{PO}_{4} / \mathrm{H}_{2} \mathrm{O}(5 \%$ : $70 \%: 25 \%$ respectively) solution was also performed at $70^{\circ} \mathrm{C}$. A $800 \mathrm{~nm}$ LPCVD amorphous silicon (a-Si) layer covered by $1 \mu \mathrm{m}$ of PECVD silicon carbide (SiC) was used as the masking layer in all experiments. This layer was patterned using $\sim 3 \mu \mathrm{m}$ resist layer and opened by reactive ion etching in Alcatel GIR 300 using mixture of $\mathrm{CF}_{4} / \mathrm{SF}_{6} / \mathrm{O}_{2}: 70 / 10 / 10$ at power of $60 \mathrm{~W}$ and pressure of $5 \mathrm{~Pa}$.

The glass etching time was selected to reach a depth of $100-120 \mu \mathrm{m}$. Stirring of solutions was provided to remove etching residuals. The etch depth and surface roughness was measured by Tencor $\alpha$-stepper and mask underetch was measured using optical microscope.

\section{Results}

Etching of Pyrex glass in $10 \%, 20 \%$ and $40 \% \mathrm{HF} / \mathrm{H}_{2} \mathrm{O}$ solutions has shown that with increase of HF concentration the roughness of etched surfaces increased. Also with increase more irregularities in etched surfaces can be observed (Fig. 1). For $20 \% \mathrm{HF}$ concentration measured roughness (Fig. 2) was up to $80 \mathrm{~nm}$. Etching of SD-2 and $\mathrm{AF}-45$ glass in $\mathrm{HF}$ solution results in formation of white particles as residuals of etching. This powder hinders further etching of the cavities and leads to non-uniform etching profiles. The Schott AF45 glass has also shown (Fig. 3) non-controllable etching with large underetch. The underetch in case of Pyrex and SD-2 glasses did not exceed the depth (aspect ratio $\sim 1$ ). In all cases some pinholes were observed across wafers after $1 \mathrm{~h}$ of etching. The etch rates for Pyrex glass in different solutions are listed in Table 4.

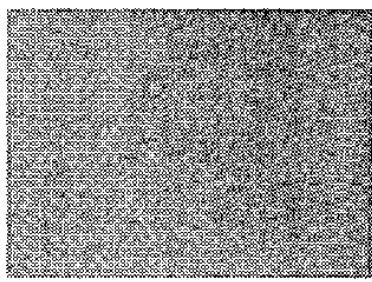

(a)

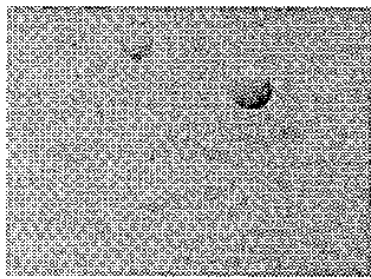

(b)
Figure 1: Optical photo of etched surface in Pyrex \#7740 glass: (a) $20 \% \mathrm{HF}$, (b) $40 \% \mathrm{HF}$.

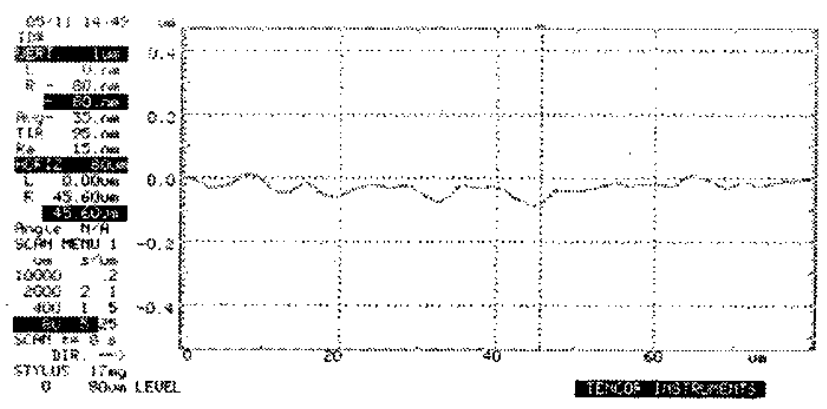

Figure 2: Profile of etched surface in $20 \% \mathrm{HF}$ solution. Measured roughness $20-80 \mathrm{~nm}$.

Table 4: Etch rate of Pyrex glass in different HF-solutions.

\begin{tabular}{|c|c|c|}
\hline Solution & $\begin{array}{c}\text { Temperature } \\
{\left[{ }^{\circ} \mathrm{C}\right]}\end{array}$ & $\begin{array}{c}\text { Etch rate } \\
{[\mu \mathrm{m} / \mathrm{min}]}\end{array}$ \\
\hline $5 \% \mathrm{HF}$ & 70 & $\sim 1$ \\
\hline $10 \% \mathrm{HF}$ & 20 & 0.4 \\
\hline $20 \% \mathrm{HF}$ & 20 & 0.8 \\
\hline $40 \% \mathrm{HF}$ & 20 & 1.55 \\
\hline $\mathrm{HF} / \mathrm{H}_{3} \mathrm{PO}_{4}$ & 70 & 1.2 \\
\hline
\end{tabular}

Etching in $\mathrm{HF} / \mathrm{H} 3 \mathrm{PO} 4$ mixture has shown better selectivity to masking layer and no pinholes were observed even after several hours of etching. Again, Pyrex \#7740 has demonstrated the smoothest surfaces after etching with roughness $\sim 10$-15nm (Fig. 4). The etching of AF45 glass was jeopardized by large number of residuals produced during etching. For SD-2, the cavities with lateral dimension $<50 \mu \mathrm{m}$ were also obstructed by residuals of etching and were etched slower and non-uniformly. Etching in pure 5\% HF solution (without $\mathrm{H} 3 \mathrm{PO} 4$ ) at $70^{\circ} \mathrm{C}$ resulted in large number of pinholes across a wafer. 


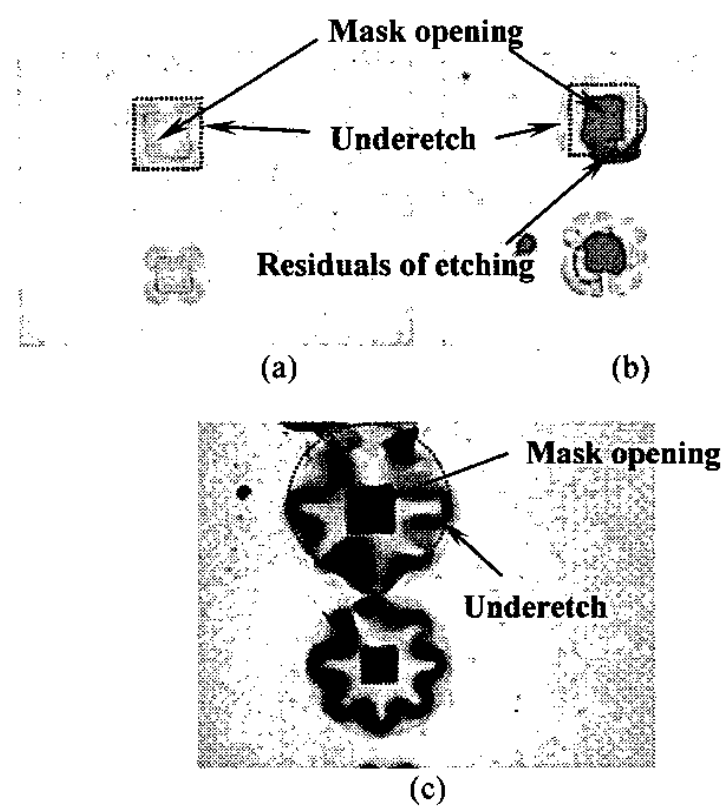

Figure 3: Optical photo of etched cavities in 20\% HF solution: (a) Pyres 7740; (b) Hoya SD-2; (c) Schott AF45 glass.

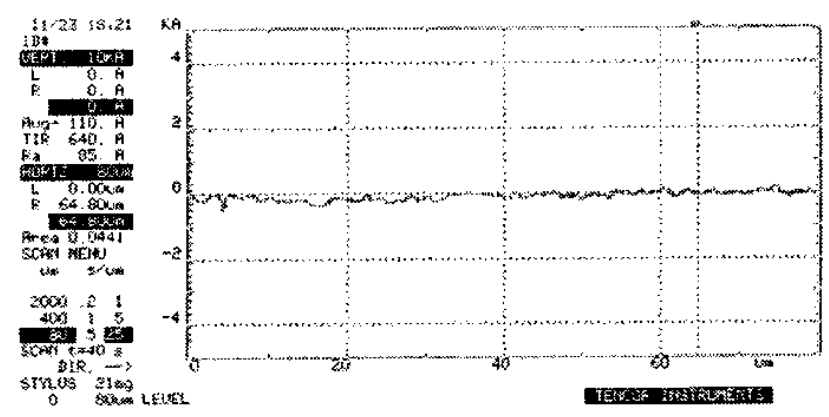

Figure 4: Profile of etched surface of Pyrex $\# 7740$ in HF $/ \mathrm{H}_{3} \mathrm{PO}_{4}$ solution. Measured roughness $10-15 \mathrm{~nm}$.

\section{Discussion}

Pyrex glass exhibits the best etching results for all glass types tested. Wet etching of AF45 in the etchants under consideration was almost impossible due to non-controllable underetch and large amount of residuals of etching. This is believed due to the presence of large amount of $\mathrm{CaO}$ in glass composition. The Hoya SD-2 glass has shown better results when etched in a HF / $\mathrm{H}_{3} \mathrm{PO}_{4}$ solution. This is because of alumina content presented in SD-2 glass is being removed by $\mathrm{H}_{3} \mathrm{PO}_{4}$ etchant while silicon dioxide is etched by $\mathrm{HF}$ etchant. The same probably occurs with Pyrex 7740. If good removal of etching residuals is provided it allows fabrication of recesses in Pyrex glass with almost optical quality of etched surfaces. It should be mentioned, that glass composition may vary across the wafer, so that if large areas are etched $\left(>1 \mathrm{~cm}^{2}\right.$ ), non-uniformity can be observed, but in the openings $<1 \mathrm{~mm}^{2}$ glass composition may be considered as constant.

\section{RF Electrical Characteristics}

We will now proceed with the description of the method adopted to obtain the electrical properties of the materials under analysis.

\section{Extraction method}

Several methods exist to obtain the electrical properties of a material. From all of them, we have chosen one that can be used to characterize thin planar materials without any special sample requirements. The electrical properties are obtained from the S-parameters measurements of a planar transmission line test-cell. The coplanar waveguide (CPW) was used because of the possibility to define a planar shape that can propagate a dominant mode (quasi-TEM). In the case of dominant mode, the coplanar characteristic impedance is quasiconstant in a broad frequency range and for a large variety of substrates and a cell structure obeying $h>S+2 W$ [7]. This cell has also the benefit of avoiding the use of vias to ground.

We will now describe the theory behind the method used to obtain the substrate properties of the different types of glasses. The geometry of the CPW cell used for S-parameter measurements is shown in Fig. 5.

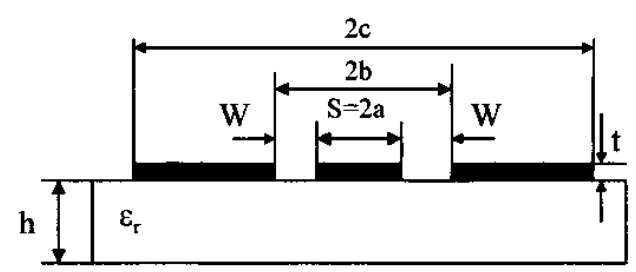

Figure 5: CPW cell used for S-parameters measurement.

For this kind of CPW, the effective dielectric constant can be obtained from [8]:

$$
\varepsilon_{r e f f}=-\left(\frac{-\ln T}{\omega d \sqrt{\varepsilon_{0} \mu_{0}}}\right)^{2}
$$

where $\omega$ is the angular frequency, $\varepsilon_{0}$ and $\mu_{0}$ are the free space permittivity and permeability, $d$ is the coplanar line length and $T$ is the transmission coefficient. The transmission coefficient can be obtained from the measured scattering parameters using the following equation [9]:

$$
T=\frac{S_{11}+S_{21}-\Gamma}{1-\left(S_{11}+S_{21}\right) \Gamma}
$$

with

$$
\Gamma=K \pm \sqrt{K^{2}-1}
$$

and

$$
K=\frac{S_{11}^{2}-S_{21}^{2}+1}{2 S_{11}}
$$

Now, with the effective electrical permittivity defined, it's possible to obtain it from the equations that characterize a coplanar waveguide with finite-width ground planes [10]. In this way, the effective electrical permittivity is given by:

$$
\varepsilon_{\text {eff }}=1+\frac{1}{2}\left(\varepsilon_{r}-1\right) \frac{K(k)}{K\left(k^{\prime}\right)} \frac{K\left(k_{1}^{\prime}\right)}{K\left(k_{1}\right)}
$$

where $\varepsilon_{r}$ is the relative permittivity of the substrate, $K$ is the complete elliptical integral of the first kind and 
$k^{\prime}=\sqrt{1-k^{2}}$ [11]. The arguments $k$ and $k^{\prime}$ are dependent on the geometry of the line and are given by [12]:

$$
k=\frac{c}{b} \sqrt{\frac{b^{2}-a^{2}}{c^{2}-a^{2}}}
$$

and

$$
k_{1}=\frac{\sinh (\pi c / 2 h)}{\sinh (\pi b / 2 h)} \sqrt{\frac{\sinh ^{2}(\pi b / 2 h)-\sinh ^{2}(\pi a / 2 h)}{\sinh ^{2}(\pi c / 2 h)-\sinh ^{2}(\pi a / 2 h)}}
$$

The characteristic impedance of the coplanar cell can also be computed from the measured S-parameters [13]:

$$
Z_{c}^{2}=Z_{0}^{2} \frac{\left(1+S_{11}\right)^{2}-S_{21}^{2}}{\left(1-S_{11}\right)^{2}-S_{21}^{2}}
$$

where $Z_{0}$ is the reference impedance $(50 \Omega)$.

To compute the attenuation we need to obtain the propagation constant $\gamma=\alpha+j \beta$ for the CPW cell. This can be computed by means of [7]:

$$
e^{-\gamma l}=\left\{\frac{1-S_{11}^{2}+S_{21}^{2}}{2 S_{21}} \pm K\right\}^{-1}
$$

where

$$
K=\left\{\frac{\left(S_{11}^{2}-S_{21}^{2}+1\right)^{2}-\left(2 S_{11}^{2}\right)^{2}}{\left(2 S_{21}^{2}\right)^{2}}\right\}^{\frac{1}{2}}
$$

Attenuation in microwave lines occurs due to radiation, metal and substrate losses. Assuming that radiation losses are very small we can obtain the dielectric loss tangent from the knowledge of the total attenuation and conductor losses.

The attenuation due to conductor losses in the center strip conductor and ground planes of a CPW is given by [14]:

$$
\alpha_{c}=\frac{R_{1}+R_{2}}{2 Z_{c}}
$$

where

$$
R_{1}=\frac{R_{S}}{8 a K^{2}(k)\left(1-k^{2}\right)}\left[\pi+\ln \frac{4 \pi a}{t}-k \ln \frac{1+k}{1-k}\right]
$$

and

$$
R_{2}=\frac{R_{s} k}{8 a K^{2}(k)\left(1-k^{2}\right)}\left[\pi+\ln \frac{2 \pi b}{t}-k \ln \frac{1+k}{1-k}\right]
$$

where the term $R_{S}$ is the skin effect surface resistance.

\section{CPW Cells Design}

The CPW cells were fabricated on three different glass substrates: non-alkaline Schott AF45, Coming Pyrex \#7740 and Hoya SD-2. The metal areas were fabricated with a $2 \mu \mathrm{m}$ aluminium layer on top of each wafer. An example of the fabricated lines is shown in Fig. 6. Since the exact electrical permittivity value at the desired frequencies was not known, several CPW cells were designed in order to obtain a suitable configuration for the material properties extraction. They were designed with different $S / W$ ratios in order to obtain different characteristic impedances. Namely, we used lines with the following dimensions: $(S=75 \mu \mathrm{m}, W=15 \mu \mathrm{m}),(S=50 \mu \mathrm{m}$, $W=35 \mu \mathrm{m}),(S=75 \mu \mathrm{m}, W=50 \mu \mathrm{m})$ and $(S=100 \mu \mathrm{m}, W=$ $60 \mu \mathrm{m})$.

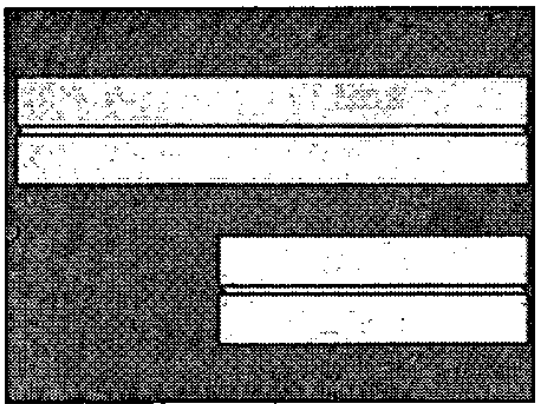

Figure 6: Example of fabricated coplanar waveguides used for $\mathrm{S}$-parameter measurement.

\section{Measurements and results}

A vector network analyzer and a probe station were used to perform the measurements on-wafer of the two-port network S-parameters. It was calibrated by means of TRL method, providing a measuring reference plane at the edge of the coplanar lines.

The accuracy of the obtained values depends significantly on the accuracy of the measured S-parameters [13]. In this way, the measured S-parameters of all the designed CPW cells had to be checked for accuracy and reliability. So, the same cells were measured more than once and the measured values that did not match from one measurement to another were discarded. Also, four different line lengths $(0.5 \mathrm{~mm}, 1$ $\mathrm{mm}, 3 \mathrm{~mm}, 5 \mathrm{~mm}$ ) were used for the same $S / W$ ratio. In this way, the calculated characteristic impedance inside the same group of coplanar lines was checked to verify the correctness of the measured values. Because the substrate losses are relatively small, lines with $5 \mathrm{~mm}$ length were used to improve the accuracy of its calculation.

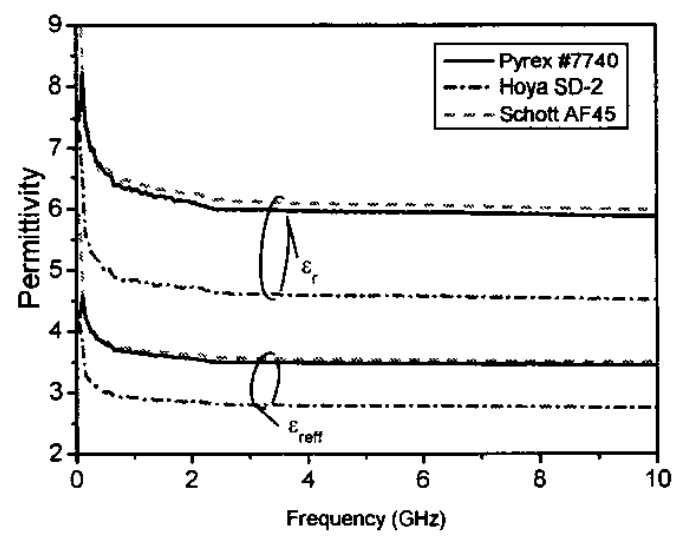

Figure 7: Measured permittivity.

After discarding the bad data, the electrical permittivity was obtained. Fig. 7 shows the results obtained from the three wafers under analysis. As can be seen from that figure, for high frequencies and as expected, the electrical properties 
have only a slight variation with frequency. We can observe an abrupt change on the measured characteristics at low frequencies. This happens because at those frequencies our assumptions are not anymore valid. At our frequencies of interest of 5-6 GHz the dielectric constants for SD-2, Pyrex and AF45 are 4.7, 5.9 and 6.1, respectively.

We have also used the measured data to compute the CPW cells characteristic impedance to validate the measured values. Figure 8 shows the values obtained for a CPW cell on different substrates.

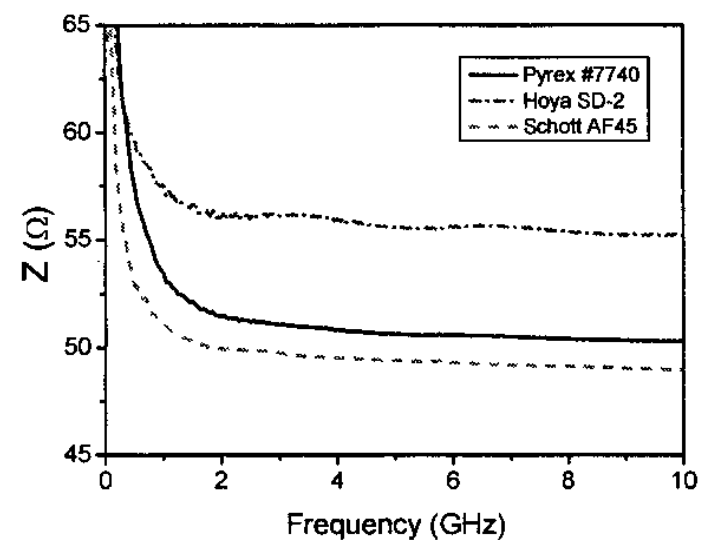

Figure 8: Measured characteristic impedance of the CPW cell with $S=75 \mu \mathrm{m}$ and $W=15 \mu \mathrm{m}$.

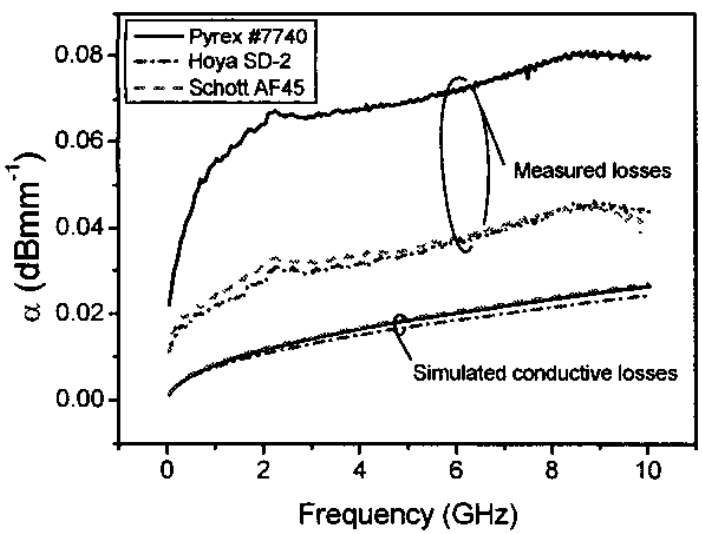

Figure 9: Computed attenuation due to conductive losses and measured total attenuation of a CPW cell with $S=75 \mu \mathrm{m}$ and $W=50 \mu \mathrm{m}$.

In Fig. 9 we plotted the measured total attenuation of a CPW cell together with the attenuation due to conductor loss, computed from (12). The difference between total losses and conductor losses give us the substrate losses. From the above figure we can see that the SD-2 and AF 45 substrates suffer from almost the same losses but the $\# 7740$ substrate have approximately twice those losses.

\section{Conclusions}

In this work, wet etching and electrical properties of three different glass substrate types, namely Pyrex \#7740, Hoya
SD-2 and Schott AF45, were investigated. They have been compared with respect to their suitability as low-loss substrates in wafer-level chip-scale packaging for RF applications. Processability has been evaluated by fabrication of shallow and deep recesses using wet etching in $\mathrm{HF}$ $\left(/ \mathrm{H}_{3} \mathrm{PO}_{4}\right)$ solutions. Electrical characteristics (dielectric constant and attenuation) have been extracted from measurements on coplanar wave guides (CPWs) up to $10 \mathrm{GHz}$. The results achieved are summarized in Table 5.

Results show that Corning Pyrex $\# 7740$ glass provides optical quality of wet-etched deep recesses, but exhibit about 2 times higher electrical attenuation than Hoya SD-2. Pyrex \#7740 and SD-2 are thermally matched to silicon and due to some alkali content, they are suitable for anodic bonding. The relatively high content of $\mathrm{Al}_{2} \mathrm{O}_{3}(\sim 20 \%)$ in SD-2 is favorable for its electrical properties. The measured attenuation on CPWs with $2 \mu \mathrm{m}$ thick $\mathrm{Al}$ metallization is less than $0.04 \mathrm{dBmm}^{-1}$ at $6 \mathrm{GHz}$. On the other hand this high $\mathrm{Al}_{2} \mathrm{O}_{3}$ content make wet etching of deep recesses more difficult. The non-alkaline AF45, with CTE almost 2 times of $\mathrm{Si}$ $\left(\mathrm{CTE}_{\mathrm{AF} 45}=4.5 \times 10^{-6} \mathrm{~K}^{-1}\right)$, is suitable for adhesive bonding and is due to high $\mathrm{CaO}$ content is difficult to pattern using wet etching. Its electrical attenuation is close to that of SD-2. The measured dielectric constants (at $6 \mathrm{GHz}$ ) for SD-2, Pyrex $\# 7740$ and AF45 are 4.7, 5.9 and 6.1, respectively.

Usage of $\mathrm{HF} / \mathrm{H}_{3} \mathrm{PO}_{4}$ solutions allows to fabricate cavities with optical quality of etched surfaces and provides better selectivity to $\mathrm{a}-\mathrm{Si} / \mathrm{SiC}$ masking layers.

Table 5: Properties of different glass types in respect to the wet etching, CTE matching to silicon and electrical properties ("++" - excellent; "--" - poor).

\begin{tabular}{|l|c|c|c|}
\hline \multicolumn{1}{|c|}{ Properties } & Pyrex 7740 & SD-2 & AF45 \\
\hline Wet etching & ++ & - & -- \\
\hline Elect. properties & + & ++ & ++ \\
\hline CTE to Si & + & ++ & - \\
\hline Anodic bonding & ++ & + & n/a \\
\hline Adhesive bonding & + & ++ & + \\
\hline
\end{tabular}

\section{Acknowledgments}

The authors wish to acknowledge the technical staff of Dimes Technology Center for their technical assistance. This work is supported by the Portuguese Foundation for Science and Technology, the European Commission and Philips Research.

\section{References}

[1] R. Dekker et al, An ultra low-power RF bipolar technology on glass, Technical Digest of IEDM, 1997, pp. 921-923.

[2] H.A.C. Tilmans et al, Wafer-level packaged RF-MEMS switches fabricated in a CMOS fab, Technical Digest of IEDM, 2001, pp. 41.4.1 -41.4.4.

[3] H. Wensink, High resolution powder blast micromachining, MEMS 2000, pp. $769-774$.

[4] X. Li et al, High density electrical feedthrough fabricated by deep reactive ion etching of pyrex glass, MEMS, 2001, pp. 98-101. 
[5] M. Stjernstrom et al, Methods for fabrication of microfluidic systems in glass, J. Micromech. Microeng, 8, 1998, pp. 33-38.

[6] R. Wuthrich et al, In situ measurement and micromachining of glass, Proceedings of Micromechatronics and Human Science, 1999, pp. 185 191.

[7] Juan Hinojosa, S-Parameter Broadband Measurements On-Coplanar and Fast Extraction of the Substrate Intrinsic Properties, IEEE Microwave and Wireless Comp. Letters, vol. 11, no. 2, 2001, pp. 80-82.

[8] Juan Hinojosa, K. Lmimouni, G. Dambrine, Fast Electromagnetic Characterization Method of Thin Planar Materials Using Coplanar Line up to V-band, Electron. Lett., vol.38, no.8, 2002, pp. 373-374.

[9] Abdel-Hakim Boughriet, Christian Legrand, Alain Chapoton, Noniterative Stable Transmission/Reflection Method for Low-Loss Material Complex Permittivity Determination, IEEE Trans. Microwave Theory Tech., vol. 45 , no. 1,1997, pp. 52-56.

[10] Rainee N. Simons, Coplanar Waveguide Circuits, Components and Systems, John Wiley \& Sons, 2001.

[11] Robert E. Collin, Foundations for Microwave Engineering, $2^{\text {nd }}$ edition, McGraw-Hill, 1992.

[12] C. Veyres, V. F. Hanna, Extension of the Application of conformal Mapping Techniques to Coplanar Lines with Finite Dimensions, Int. J. Electron., vol. 48, no. 1, 1980.

[13] William R. Eisenstadt, Yungseon Eo, S-Parameter-Based IC Interconnect Transmission Line Characterization, IEEE Trans. Components, Hybrids, and Manufact. Techn., vol. 15 , no. 4, 1992, pp. 483-489.

[14] Yi-Chi Shih, "Broadband Characterization of ConductorBacked Coplanar Waveguide Using Accurate On-Wafer Measurement Techniques", Microwave Journal, vol. 34, no. 4, 1991, pp. 95-105. 